\title{
POR QUE CULTURA SURDA?: Sentidos e significados na educação de alunos surdos
}

\section{WHY DEAF CULTURE?: Senses and meanings in the education of deaf students ¿POR QUÉ LA CULTURA SORDA?: Sentidos y significados en la educación de los alumnos sordos}

\author{
Rosana Prado \\ Doutora em Educação, Universidade Federal Fluminense (UFF). \\ Professora adjunta do Departamento de Ensino Superior do Instituto de Educação de Surdos/INES. \\ Professora do Curso de Mestrado Profissional em Diversidade e Inclusão (UFF). \\ rosanaprado.I.m@gmail.com \\ Valdelúcia Alves da Costa \\ Docente da Universidade Federal Fluminense (UFF), atuante no curso de Pedagogia e no \\ Programa de Pós-graduação em Educação, Faculdade de Educação (UFF). \\ valdeluciaalvescosta@id.uff.br
}

\begin{abstract}
RESUMO: Na intenção de discutir sobre a educação de alunos surdos na perspectiva da educação bilíngue, fezse necessário refletir sobre as concepções de cultura ao longo das experiências sociais vividas pela humanidade; assim como sobre a questão da constituição das identidades no mundo globalizado e administrado pela lógica capitalista. Foi considerada a Teoria Crítica da Sociedade como referencial de análise e a escola como espaço de reflexão e crítica às ações de dominação cultural, visando compreender suas causas e, assim, não permitir sua reprodução, como também foi considerada a educação de alunos surdos que respeite as singularidades da língua e cultura da comunidade surda e o bilinguismo como opção metodológica de atendimento às demandas dos alunos surdos na organização de escolas bilíngues.
\end{abstract}

PALAVRAS-CHAVE: Cultura surda. Educação bilíngue. Alunos surdos.

ABSTRACT: In order to discuss education of deaf students from the perspective of bilingual education, it was necessary to reflect on the conceptions of culture throughout social experiences lived by mankind; As well as on question of the identity constitution in the globalized world and administered by capitalist logic. The Critical Theory of Society was considered as a reference for analysis and the school as a space for reflection and criticism of acts of cultural domination, aiming at understanding causes and, therefore, not allowing their reproduction, but also considering the perspective of education of deaf students which respects singularities of language and culture of the deaf community and bilingualism as a theoretical-methodological option to meet demands of deaf students in the organization of bilingual schools.

KEYWORDS: Deaf culture. Bilingual education. Deaf students.

RESUMEN: Con la intención de discutir la formación de los alumnos sordos en el contexto de la educación bilingüe, fue necesario reflexionar sobre las concepciones de la cultura a través de las experiencias sociales vividas por la humanidad; así como sobre la cuestión de la constitución de las identidades en un mundo globalizado y administrado por la lógica capitalista. Se consideró la Teoría Crítica de la Sociedad como aporte de análisis y la escuela como un espacio de reflexión y crítica de las acciones de dominación cultural con el fin de comprender sus causas y, por lo tanto, no permitir su reproducción, como también se consideró la educación de alumnos sordos que respete las singularidades de la lengua y la cultura de la comunidad sorda y el bilingüismo como una opción metodológica en el atendimiento de las demandas de los alumnos sordos en la organización de las escuelas bilingües.

PALABRAS CLAVE: Cultura sorda. Educación bilingüe. Alumnos sordos.

\footnotetext{
${ }^{1}$ Este artigo deriva-se de minha tese de doutorado, intitulada 'Políticas de Inclusão e Práticas Pedagógicas na Educação de Alunos Surdos: Programa de Bilinguismo de Niterói/RJ', elaborada sob a orientação da Profa. Dra. Valdelúcia Alves da Costa, com bolsa da CAPES, defendida em 2014, no Programa de Pós-graduação em Educação, Faculdade de Educação, Universidade Federal Fluminense (UFF). Disponível em: http://www.lapeade.com.br/publicacoes/tesesedissertacoes/DOUTORADO\%20 ONEESP-OEERJ\%20-UFF-RosanaMeireles-ValdeluciaAlvesCosta-2014.pdf
}

Artigo recebido em setembro de 2016

Aprovado em novembro de 2016 


\section{1| INTRODUÇÃO}

Para iniciar a discussão sobre cultura surda faz-se necessárioconsideraras diversas concepções de cultura e sua relação com a sociedade e a história. A discussão e reflexão sobre cultura demandam levar em conta sua presença nas diferentes áreas do conhecimento como a sociologia, a filosofia, antropologia, história, comunicação, dentre outras. Dessa maneira, cada uma dessas áreas atribui um sentido ao termo, de acordo com sua especialidade e referencial de análise. Para além das diversas áreas do conhecimento humano deve-se considerar o próprio desenvolvimento histórico do termo.

De acordo com Cevasco (2003), a palavra cultura entrou na língua inglesa a partir do latim colore que significa habitar - hoje, colono e colônia. Até o século XVIII o termo era entendido com o sentido de cuidar de algo, seja com animais, com a colheita ou para se referir a algo como parcela de uma terra cultivada.

Durante o Romantismo, o termo cultura passou a ser usado em oposição ao seu sinônimo civilização - como um caminho para enfatizar a cultura das nações e do folclore e, portanto, o domínio do caráter humano em oposição à ideia mecânica de civilização, que se destaca no século XVIII com a industrialização. Ao longo do século XIX ganha significado um novo conceito de cultura. Começou a ser utilizado como substantivo abstrato, para referir-se não a uma ação mecânica, mas para designar um processo de desenvolvimento intelectual e espiritual. Na metáfora ao sentido de cuidar de algo, considerou-se o empenho para o desenvolvimento das faculdades humanas relacionadas ao desenvolvimento intelectual, espiritual e estético, e em consequência, se remete às obras e atividades artísticas que passam a representar a própria cultura. Assim, de acordo com Chauí (2008, p. 55):

A cultura passa a ser encarada como um conjunto de práticas (artes, ciências, técnicas, filosofia, os ofícios) que permite avaliar e hierarquizar o valor dos regimes políticos, segundo um critério de evolução. No conceito de cultura introduz-se a ideia de tempo, mas de um tempo muito preciso, isto é, contínuo, linear e evolutivo, de tal modo que, pouco a pouco, cultura torna-se sinônimo de progresso. Avalia-se o progresso de uma civilização pela sua cultura e avalia-se a cultura pelo progresso que traz a uma civilização.

As sociedades passaram a ser consideradas segundo a presença ou a ausência de alguns elementos, próprios de uma determinada sociedade e a ausência desses elementos é considerada ausência de cultura ou de evolução. Em outras palavras, segundo Chauí (2008), foi introduzido um conceito de valor para distinguir as formas culturais.

No século XIX a cultura ganha caráter de algo que é próprio da humanidade e é elaborada como a diferença entre natureza e história. A ordem biológica do ser é regida pela natureza e está restrita às manifestações de adaptação ao meio. No entanto, a ordem humana é de natureza simbólica e requer a capacidade humana de relacionar-se com elementos que não estão presentes por meio da linguagem e do trabalho em sociedade. Nessa perspectiva, Chauí afirma que (2008, p.56):

A dimensão humana da cultura é um movimento de transcendência, que põe a existência como o poder para ultrapassar uma situação dada graças a uma ação dirigida àquilo que está ausente. Por isso mesmo somente nessa dimensão é que se poderá falar em história propriamente dita. Pela linguagem e pelo trabalho o corpo humano deixa de aderir imediatamente ao meio, como o animal adere. Ultrapassa os dados imediatos dos sinais e dos objetos de uso para recriá-los numa dimensão nova.

Essa nova concepção de cultura foi incorporada a partir da segunda metade do século XX, 
pelos antropólogos europeus. Por meio de uma concepção menos etnocêntrica inaugura-se a antropologia social e a antropologia política, nas quais a cultura é determinada histórica e materialmente como possuidora de uma ordem humana simbólica com estrutura própria e individual. Dessa maneira, o termo cultura passa a ser entendido como produção e criação de linguagem, da religião, da sexualidade, das formas de viver em sociedade, das expressões da música, da dança, do lazer e da maneira como o ser humano se relaciona e se manifesta em sociedade, como destacado por Chauí (2008, p.57):

A cultura passa a ser compreendida como o campo no qual os sujeitos humanos elaboram símbolos e signos, instituem as práticas e os valores, definem para si próprios o possível e o impossível, o sentido da linha do tempo (passado, presente e futuro), as diferenças no interior do espaço (o sentido do próximo e do distante, do grande e do pequeno, do visível e do invisível), os valores como o verdadeiro e o falso, o belo e o feio, o justo e o injusto, instauram a ideia de lei, e, portanto, do permitido e do proibido, determinam o sentido da vida e da morte e das relações entre o sagrado e o profano.

Considerando tais perspectivas, a partir de uma breve consideração a respeito do conceito de cultura, concordando com Cevasco (2003,p. 11) ao declarar que "O sentido das palavras acompanha as transformações sociais ao longo da história e conserva, em suas nuanças e conotações, muito dessa história". Percebe-se que para pensar o conceito de cultura torna-se significativa a análise do momento histórico-social no qual se insere esse conceito.

Em autores contemporâneos como Larraya (2009) Chauí (2008), Silva, Hall \&Wodward (2011), entre outros, encontramos elementos à reflexão proposta, na intenção de pensar sobre a existência de uma cultura surda. Assim, Larraya (2009) considera que para as Ciências Sociais, sobretudo conforme as formulações de Tylor, cultura é um conjunto de ideias, comportamentos, símbolos e práticas sociais artificiais, aprendidos de geração em geração por meio da vida em sociedade.

De acordo com Larraya (2009) o conceito de cultura, utilizado atualmente, foi definido pela primeira vez por Taylor se referindo a um conjunto de manifestações humanas que contrasta com a natureza ou comportamento natural. Considerando esta como um conjunto de respostas para melhor satisfazer as necessidades e os desejos humanos, abrangendo em uma única palavra, todas as possibilidades de realização humana, além de marcar fortemente a oposição do caráter do aprendizado da cultura em oposição à ideia de aquisição inata, transmitida por mecanismos biológicos.Avançando no conceito de cultura, consideramos que para Wodward (2011, p. 89):

\begin{abstract}
Cada cultura tem suas próprias e distintas formas de classificar mundo. É pela construção de sistemas classificatórios que a cultura nos propicia os meios pelos quais podemos dar sentido ao mundo social e construir significados. Há, entre os membros de uma sociedade, um certo grau de consenso sobre como classificar as coisas a fim de manter alguma ordem social. Esses sistemas partilhados de significação são, na verdade, o que se entende por cultura.
\end{abstract}

Portanto, a cultura contribui na intermediação para a experiência dos indivíduos. A priori, a cultura fornece algumas categorias e padrões pelo quais os valores são organizados socialmente. $\mathrm{E}$, de certa maneira, adquire autoridade no pacto social, uma vez que é admitida pela maioria dos grupos sociais.

No que se refere às influencias da cultura na sociedade, faz-se necessário refletir sobre os pressupostos da cultura à luz da teoria crítica da sociedade, como afirmado por Adorno²:

${ }^{2}$ Disponível em http://adorno.planetaclix.pt/tadorno.htm com acesso em 01/10/2016. 
A formação cultural agora se converte em uma semiformação socializada, na onipresença do espírito alienado, que, segundo sua gênese e seu sentido, não antecede à formação cultural, mas a sucede. Deste modo, tudo fica aprisionado nas malhas da socialização.

Assim, é necessária a reflexão acerca da dominação da cultura sobre o indivíduo e a submissão do pensamento aos padrões estabelecidos pela sociedade administrada e controlada pelos padrões de competição e acumulação capitalista. No tocante aos indivíduos surdos essa socialização sempre esteve condicionada aos padrões de comportamento e eficiência estabelecidos pelos e para os ouvintes. A crítica à adaptação ao mundo administrado de Adorno ${ }^{3}$ reitera que:

(...) nos casos em que a cultura foi entendida como conformar-se à vida real, ela destacou unilateralmente o momento da adaptação, e impediu assim que os homens se educassem uns aos outros. Isso se fez necessário para reforçar a unidade sempre precária da socializaçãoe para colocar fim àquelas explosões desorganizadoras que, conforme é óbvio, se produzem às vezes justamente onde já está estabelecida uma tradição de cultura espiritual autônoma.

Nesse sentido, a cultura considerada como simples adaptação à sociedade, submete os indivíduos surdos a uma socialização precária e condicionada aos padrões dominantes. Para Adorno (2006) a adaptação vai variar em função do tempo e da cultura, mas o indivíduo deve se formar para pensar livremente, se reconhecer na cultura e compreender os limites sociais e regras estabelecidas pelas instâncias sociais, sem se submeter.Para Adorno (2006, p. 143-144):

A educação seria impotente e ideológica se ignorasse o objetivo de adaptação e não preparasse os homens para se orientarem no mundo. Porém ela seria igualmente questionável se ficasse nisto, produzindo nada além de pessoas bem ajustadas. A adaptação não deve conduzir a perda da individualidade em conformismo uniformizador.

A adaptação, que não é consciente, fragiliza os egos tornando os indivíduos massa de manobra nas mãos dos que manipulam a favor dos interesses de uma minoria social dominante. Faz-se necessário educar os indivíduos para a autonomia. A adaptação é importante e necessária para o entendimento do sistema social e para a resistência. Porém, a mera adaptação leva à reprodução social, contribuindo para a regressão. $O$ indivíduo precisa se adaptar para aprender a se orientar no mundo, pois ao negar a cultura não poderá contribuir para sua diferenciação por intermédio da imersão nela. Assim, Adorno 4 destaca que: "A diferença sempre crescente entre o poder e a impotência sociais nega aos impotentes - e tendencialmente também aos poderosos — os pressupostos reais para a autonomia que o conceito de formação cultural ideologicamente conserva".

Dessa maneira, afirma-se a necessidade de uma adaptação que não impeça o indivíduo de atuar criticamente na sociedade em que vive, porque a consciência crítica é que dá sentindo à sua condição histórica e cultural. Toda vez que se suprime a liberdade do homem, este se torna um ser meramente acomodado e ajustado e, por consequência, cerceado em seu direto de exercer a capacidade de criação e decisão na cultura da qual é partícipe. A luta do homem faz-se assim, a luta que o permita ir além da adaptação e acomodação, para ir ao encontro de sua humanização, ameaçada constantemente pela opressão do capital. E analogamente poder-se-ia dizer que a luta dos indivíduos surdos é uma luta que o permita ir além de uma acomodação aos padrões de sociedade majoritariamente ouvinte, para ir ao encontro de sua identidade surda, ameaçada pela opressão da sociedade ouvinte administrada.

\footnotetext{
${ }^{3}$ Disponível em http://adorno.planetaclix.pt/tadorno.htm com acesso em 01/10/2016.

${ }^{4}$ Disponível em http://adorno.planetaclix.pt/tadorno.htm com acesso em 01/10/2016.
} 


\title{
2 | FORMAÇÃO DE IDENTIDADES NA CULTURA SURDA
}

As sociedades modernas vivem sob o fenômeno da globalização, onde tudo é dinâmico e em permanente processo de mudança. A sociedade se constrói e reconstrói em meio a constantes rupturas e fragmentações em seu próprio interior. O processo de modernização pelo qual passou (e continua passando) o mundo foi uma imposição do sistema capitalista que está sempre criando mecanismos de sobrevivência e manutenção. $\mathrm{Na}$ atualidade tudo é mutável e dinâmico porque esta é uma necessidade imposta pelo capitalismo moderno que forja necessidades aos indivíduos para sua dominação e inconsciência dos limites sociais. A instabilidade social, econômica e política é a lógica do momento. Não se tem garantia de absolutamente nada sob a égide do capital. O provisório e o aligeiramento regem as relações sociais e a formação do indivíduo que se encontram submetidos à ideia de transitoriedade e da necessidade de mais consumo de mercadorias produzidas pela indústria cultural, como problematizado por Horkheimer e Adorno (2002, p. 7) "A cultura contemporânea a tudo confere um ar de semelhança. Filmes, rádio e semanários constituem um sistema. Cada setor se harmoniza em si e todos entre si".

Para Crochík (2006), a identidade individual é formada por elementos visíveis e invisíveis, constantes e imprevisíveis, sociais e individuais, manifestos e ocultos, universais e particulares, permanentes e em mutação. Nesse caso, os elementos permanentes não podem ser desconsiderados, uma vez que caracterizam a memória, as experiências acumuladas por um indivíduo, refletidas ou não. Por outro lado, desconsiderar as possibilidades de mudanças e reconstruções significativas em suas concepções, valores e atitudes, é julgar que o indivíduo não tenha capacidade de ser outra coisa, além daquilo que se espera dele.

Crochík (2006) considera duas esferas na construção de identidade do indivíduo. Para ele, o indivíduo está imerso na cultura e sujeito ao processo de mutabilidade imposto pela sociedade moderna e pelo processo de globalização, como considerado por Hall (2006). Mas, não desconsidera a esfera de experiências pessoais que alicerçam a história de cada indivíduo. Portanto, Crochík (2006, p.67) defende que:

\begin{abstract}
O indivíduo se constitui em uma identidade, não a tem desde o princípio. Antes mesmo de se identificar com o seu nome, o indivíduo participa das relações sociais que the dão sentido, o que nos impede de considerá-lo abstratamente uma mônada, ou seja, fechado em si mesmo e com um princípio de determinação interno. Ele se constrói em relação a um mundo social já construído que tem predominância sobre ele.
\end{abstract}

É possível afirmar, de acordo com Crochík (2006), que a identidade do indivíduo se forma considerando elementos permanentes e em mutação, ou seja, o indivíduo tem experiências acumuladas em sua memória e essas servem de alicerce para novas tomadas de atitudes e novos direcionamentos que estão em constante mutabilidade. Embora havendo concordância nos pensamentos de Hall (2006) e Crochík (2006), no que se refere à constante modificação das maneiras como os indivíduos se reconhecem no mundo, Crochík vai além, considerando uma esfera que é particular e permanente, que se caracteriza pela memória das experiências vividas.

Crochík (2006, p.127), ao referir-se a Freud, destaca que:

O eu, é produto de múltiplas identificações, obtidas em diversos grupos e instituições dos quais o indivíduo faz parte. A sua originalidade se deve a forma de expressa-las, por aquilo que tem de próprio, não sendo, portanto, mera cópia dos objetos com os quais se identificou. 
O pensamento de Crochík vem afirmar o pensamento de Hall (2006) no que se refere à fragmentação e multiplicidade na formação da identidade do indivíduo. O indivíduo forma a sua identidade com base nas experiências vividas nos variados grupos nos quais convive. $O$ indivíduo não tem um eu unificado e autônomo da sociedade e da cultura nas quais está inserido. Mas, é produto das diversas identificações que desenvolve ao longo de suas experiências. Porém, não deixando de considerar a existência de uma originalidade, que é própria de cada indivíduo, uma vez que este não apenas reproduz a lógica social vigente, mas se relaciona com ela exercendo influência.

Com base nessas reflexões, pode-se pensar na construção da identidade dos indivíduos surdos. Sabe-se que os indivíduos surdos possuem como língua natural a língua de sinais, que é uma língua gestual-visual e que confere a eles uma apropriação visual da sociedade na qual estão inseridos. Portanto, a construção de identidade destes indivíduos se dará por meio de interações visuais com o meio.

\section{3| AFINAL, POR QUE CULTURA SURDA?}

Antes mesmo da problematização sobre cultura surda, faz-se necessário considerar que os surdos são indivíduos do mundo moderno e sujeitos às fragmentações e instabilidades socialmente impostas. O indivíduo surdo constrói sua identidade com base em interações visuais. Mas, também imerso em uma cultura que o torna, religioso, estudante, trabalhador, membro de uma família, seguidor de uma tradição, submetidos às regras e convenções sociais, entre outras.

Uma questão importante para pensar sobre o indivíduo surdo se refere à maneira como este se relaciona com o mundo e no acesso que terá às informações e possibilidades ou não de interagir com outros indivíduos. No mundo globalizado e constituído por acessos rápidos e contínuos, por intermédio da internet e outros meios tecnológicos há que se questionar: Até que ponto essa globalização chega aos indivíduos surdos? Muitos indivíduos surdos, ainda, não têm acesso à sua língua natural e, por consequência, não dispõem de possibilidades de interlocução com o meio social. Sem linguagem, esses indivíduos não desenvolvem as funções planejadoras e organizadoras do pensamento, o que os limita na construção de suas identidades e participação social com autonomia.

Quanto a isso, Meireles (2010), considera que os movimentos de globalização no mundo em constante modificação em busca pela homogeneização, no que se refere aos indivíduos surdos, se voltam mais para seu enquadramento nos padrões sociais do que em propiciar o acesso e permanência em instâncias, como a escola e o mundo do trabalho. No Brasil, a regulamentação da Língua Brasileira de Sinais/LIBRAS e sua utilização nos diferentes espaços sociais representou avanço considerável. Porém, segundo Dorziat (2009, p.23):

Considerando as ambiguidades e contradições inerentes a uma cultura erigida sob os princípios das identidades universais que cultivam as relações de poder, a Libras toma corpo apenas de um aparato legal, de uma ferramenta de valor simbólico para mascarar a continuidade das políticas homogêneas e unilaterais. Desse modo se acata a diferença, mas mantém-se o mesmo tipo de submissão dos indivíduos às estruturas existentes.

Apesar da LIBRAS ter sido regulamentada e dos surdos terem direito ao acesso de todas as informações por seu intermédio, as relações de poder continuam erigidas sob a lógica de dominação ao que é padronizadamente aceito pela sociedade. Assim, o modelo ideal de indivíduo continua 
baseado na reprodução de uma lógica ouvintista ${ }^{5}$. As pessoas surdas têm na LIBRAS a representação de sua existência e a construção subjetiva de suas personalidades, que segundo Dorziat (2009, p.55):

\begin{abstract}
Volta-se à velha e carcomida ideia de comunidades enquanto união de culturas unificadas, sem considerar que elas são atravessadas por profundas divisões e diferenças internas e são 'unificadas' apenas através de exercícios de poder cultural variados. As identidades surdas estão permeadas também por outras diferenças e compõem as adversidades presentes no jogo de poder, nas divisões e contradições internas.
\end{abstract}

Dessa maneira, sabe-se que as identidades surdas são formadas com base, não apenas na surdez, mas nas diversas diferenças que permeiam o social. É importante lembrar que segundo Skliar (2005), além dos indivíduos surdos possuírem potencialidade para aquisição de uma língua de sinais, também têm o direito de se desenvolverem em uma comunidade de pares e de terem oportunidades de identificação com o processo sócio histórico no qual se inserem.

\title{
4 | AFINAL, POR QUE CULTURA SURDA?
}

Diante da afirmação da cultura surda, percebe-se que alguns autores divergem em suas concepções levando a um tensionamento na área. Muitos autores como Quadros (2008), Skliar (2005) e Dorziat (2009), fundamentam a existência de uma cultura surda e de direito dos indivíduos surdos. No entanto, outros autores, em menor número, como Santana e Bergamo (2005) e Bueno(1998), argumentam que os indivíduos surdos, assim o são por uma patologia e o fato de não possuírem a audição, não os deve isolar dos valores sociais da sociedade majoritária.

De acordo com Bueno (1998) todas as evidências científicas, sociais e culturais indicam que a surdez é uma deficiência e que devemos empreender esforços para evitá-la. Segundo o autor, as vacinas contra rubéola e outras formas de prevenção da surdez devem ser implementadas porque previnem os fatores que podem ocasionar a surdez. Isso é, previnem um mal. Bueno (1998, p.13) destaca ainda que: "Considerar o surdo como grupo minoritário pode ser importante do ponto de vista das diferenças culturais, mas confundi-los com outros grupos minoritários é esconder uma distinção entre o patológico e a mera deficiência". Dessa maneira, Bueno entende que se a surdez passar a ser entendida como uma simples diferença, qualquer ação contra a sua incidência deverá ser combatida. Se de alguma maneira, existe um acordo na intenção de prevenir ou erradicar adversidades e patologias que possam ocasionar a surdez, então ela deverá ser considerada como um mal a ser evitado. Nesse sentido, Bueno (1998, p.14) afirma que:

O problema com relação à surdez, assim como para as deficiências em geral, é que, como ela não afeta diretamente as possibilidades de sobrevivência e, em grande parte dos casos, até o momento atual, não é passível de reversão, há que se encontrar formas democráticas de conviver com os surdos. Assim, parece-me acertado procurar distinguir a surdez da doença, mas não se pode deixar de considera-la como uma condição intrinsecamente adversa (diferente da negritude ou do homossexualismo).

\footnotetext{
${ }^{5}$ Quando se fala em ouvintismo, segundo Skliar (2005, p.15), trata-se de um conjunto de representações dos ouvintes a partir do qual o surdo está obrigado a olhar-se e a narrar-se como se fosse ouvinte. Além disso, é nesse olhar e nesse narrar-se que acontecem as percepções do ser deficiente, do não ser ouvinte; percepções que legitimam as práticas terapêuticas habituais.
} 
Bueno empenha-se em fundamentar a surdez como algo que não deve ser desejado e sim evitado. Uma vez que, na maioria das vezes, é resultado de uma adversidade como doenças, acidentes, problemas no parto e outras situações que não se deseja viver. No entanto, uma vez que o indivíduo nasça com a surdez ou fique surdo, posteriormente, esta se torna irreversível e o indivíduo não pode ser visto como uma pessoa doente em sua totalidade, porque de fato não o é.

De acordo com as considerações de Bueno, percebe-se quanto o discurso patológico ainda pesa sobre as pessoas surdas, sua história e sua luta para se constituírem no que são em termos de identidade e participação social. Nessa perspectiva, Lopes (2011, p. 16) acrescenta que:

(...) entender a surdez como um traço cultural não significa retira-la do corpo, negando seu caráter natural; nem mesmo significa o cultivo de uma condição primeira de não ouvir. Significa aqui pensar dentro de um campo em que sentidos são construídos em um coletivo que se mantém por aquilo que inscreve sobre a superfície de um corpo.

Nessa perspectiva, surdez pode ser entendida não como uma oposição entre corpo eficiente ou deficiente, mas dentro de um campo de ações construídas pela linguagem, pois é a linguagem que permite a constituição de um conjunto de significações e representações sobre as maneiras de se relacionar com o mundo e consigo mesmo.

Ainda sobre cultura surda, Skliar (2005, p.28) considera que:

Para muitos resulta curiosa e, para outros, decididamente incômoda, a referência a uma cultura surda. Em menor grau ainda, se discute hoje a existência de uma comunidade de surdos. Talvez, resulte fácil definir e localizar no tempo e no espaço, um grupo de pessoas; mas, quando se trata de refletir sobre o fato de que nessa comunidade surgem - ou podem surgir - processos culturais específicos, é comum a rejeição da ideia da "cultura surda", trazendo como argumento a concepção de cultura universal, a cultura monolítica.

Concordando com Skliar, reconhecemos que é mais fácil identificar um grupo de pessoas quando estas não ameaçam os processos culturais majoritários e o quanto desafiadora é a proposta de uma cultura surda para os indivíduos que não viveram experiências na cultura surda. Para Adorno (2006, p.148) "O defeito mais grave com o que nos defrontamos atualmente, consiste em que os homens não são mais aptos à experiência, mas interpõe entre si mesmos e aquilo a ser experimentado aquela camada estereotipada a que é preciso se opor". Portanto, o ser humano como ser social não vive experiências puras, mas sim intermediadas pelos estereótipos estabelecidos pela cultura majoritária. Então, considerar a cultura surda pode significar a possibilidade de viver experiências com a surdez e admitir a afirmação do que é desconhecido e, consequentemente, ameaçador. De acordo com Lopes (2011) "Não há como fazer significações sem que haja conhecimentos, representações sobre o que é ser surdo e o que seja a surdez". As argumentações anteriores nos levam a pensar que a negação da cultura surda constitui-se como ausência de experiência com os surdos e a surdez.

Continuando a reflexão sobre cultura surda, consideramos importante destacar a afirmativa de Skliar (2005, p. 146), ao considerar que:

O que a cultura ouvinte elitista ocidental tenta perpetuar é a afirmação de um padrão cultural único, visto como melhor para toda sociedade global. Esta visão de padrão cultural único leva ao paradoxo da interdição do acesso a essa cultura "melhor", tanto por parte dos surdos aos próprios surdos, quanto pelas classes desfavorecidas de uma sociedade a si mesma. 
Portanto, a visão da surdez como uma questão intrinsecamente adversa, conforme destaca Bueno (1998) faz parte de um discurso que perpetua a cultura ouvinte elitista como afirmação de um padrão cultural dominante. Estudos recentes como os de Skliar (2005), Dorziat (2009), Meireles (2010) e Lopes (2011), entre outros, constatam que os surdos se identificam com seus pares e se constituem na experiência visual, que é diversa da experiência auditiva. Então, se a surdez fosse, apenas, uma patologia, uma ausência de um sentido que o ser humano, normalmente, possui e se deve ser combatida a incidência de adversidades que ocasionam a surdez, o que poderia explicar a total identificação de alguns indivíduos com o fato de ser surdo?

Para responder essa pergunta, pode-se considerar que nem todos os surdos assim o são por motivo de doença ou adversidade. Existem, embora em menor número, indivíduos surdos que nascem em famílias de surdos. Ou seja, percebem-se casos em que a surdez manifesta-se de forma hereditária. Principalmente, nesses casos, os indivíduos surdos nascem e crescem em uma comunidade de pares em que a maioria utiliza a língua de sinais.

No entanto, esta não é a realidade da maioria dos indivíduos surdos. Grande parte destes nasce em família de ouvintes, onde a maioria é usuária de uma língua oral e de onde se origina toda a dificuldade que têm em estabelecer trocas simbólicas com o grupo do qual são constituintes. Embora, a maioria dos surdos seja de família ouvinte, estes tendem a se identificar com outros indivíduos surdos pelo uso de uma língua em comum, pela apropriação visual que têm da realidade, por valores, interesses, hábitos e costumes que se constroem a partir dessa apropriação visual diferenciada da realidade.

De acordo com Goldfeld (2002), mesmo que a surdez se origine de uma patologia, uma vez surdo, o indivíduo tem plenas condições de desenvolvimento, caso tenha acesso a uma língua que lhe sirva de suporte de pensamento e de comunicação. Sendo assim, a surdez passa a ser vista não como uma adversidade e sim como uma característica que difere, mas não incapacita para vida autônoma em sociedade.

A partir do enfoque dado anteriormente à cultura, passemos a reflexão estabelecida por Sá (2006) a respeito de cultura surda. De acordo com a autora, os indivíduos surdos formam grupos sociais diferentes daqueles que escutam. Para ela, a surdez leva os indivíduos a constituírem maneiras próprias de organização, de solidariedade, de linguagem, de juízos, de valores, de arte, entre outros e, portanto, a surdez é uma diferença construída historicamente com base em conflitos sociais e ancorada em práticas de significações visuais, próprias aos indivíduos surdos.

Para Sá (2006), assim como para autores, como Quadros (2008), Skliar (2005) e Dorziat (2009) o uso da língua de sinais configura-se como importante fator a ser considerado na significação de cultura surda, mas não o único. A formação de identidade e o sentimento de pertencimento a uma cultura se constroem nas relações que se estabelecem socialmente. De acordo com Santana e Bergamo (2005, p. 568):

\footnotetext{
A identidade seria uma construção permanente (re)feita que buscaria tanto determinar especificidades que estabeleçam fronteiras identificatórias entre o próprio sujeito e o outro quanto obter o reconhecimento dos demais membros do grupo social ao qual pertence. Seria, portanto, nessa relação, no tempo e no espaço, com diferentes outros que o sujeito se construiria. É, com isso, nas praticas discursivas que o sujeito emerge e é revelado. Ou seja, é principalmente no uso da linguagem - e não qualquer materialidade linguística específica - que as pessoas constroem e projetam suas identidades.
}

Portanto, pode-se considerar que os surdos constituem identidade e significam o mundo por meio das relações que estabelecem com os outros seres sociais. Continuando na mesma linha de pensamento, Santana e Bergamo afirmam que a constituição da identidade pelo surdo não se 
estabelece unicamente pela língua de sinais, mas sim pela presença de uma língua que os permita constituir-se no mundo como 'falantes'. Assim, a subjetividade desses indivíduos se constrói pela linguagem e estas implicam em suas relações sociais. Segundo Porche (2005, p.572) cultura deve ser entendida como: "Esquemas perceptivos e interativos segundo os quais um grupo produz o discurso de sua relação com o mundo e com o conhecimento". Para esses autores, a língua é um recurso na produção da cultura, embora não seja o único.

Quando autores como Skliar (1998) e Sá (2006) defendem a necessidade de afirmar a existência de uma cultura surda, o fazem com base nas diversas significações visuais que esses indivíduos estabelecem com seu entorno social por meio da língua de sinais. Avançando na análise, Skliar(2005, p.27) afirma que:

\begin{abstract}
Não estou simplesmente mencionando o processo individual ou individualizado de identificações, como se elas fossem homogêneas, estáveis, fixas, como se a identificação entre surdos ocorresse de forma inevitável, uma vez que a "surdez os identifica". Refiro-me sim a uma política de identidades surdas, onde questões ligadas à raça, à etnia, ao gênero, etc, sejam também entendidas como "identidades surdas"; identidades que são, necessariamente, híbridas e estão em constante processo de transição.
\end{abstract}

Nessa perspectiva, percebe-se que as pessoas surdas estão imersas em sociedade e se identificam com outros indivíduos no que se refere à raça, etnia, profissão, religião, sexo, entre outros. Mas, e quanto ao que os identifica como indivíduos surdos, pertencentes a uma cultura visual? As potencialidades visuais dos indivíduos surdos não podem ser entendidas unicamente com base em um sistema linguístico próprio da língua de sinais. A surdez é uma experiência visual e isso significa que todas as interações, subjetivações e identificações com as instâncias sociais se darão pelas experiências visuais. As identificações que o indivíduo surdo estabelecerá em relação ao sexo, à raça, à família, à sociedade e ao mundo, acontecerão por intermédio de experiências visuais.

Segundo Skliar (2005, p.28), "Não é possível aceitar, de forma alguma, o visual da língua de sinais e disciplinar a mente e o corpo das crianças surdas como sujeitos que vivem uma experiência auditiva." Nesse sentido, a escola, a família e as experiências propostas aos alunos surdos devem ser pensadas como experiências visuais. Caso contrário, não possibilitarão a construção do conhecimento pelos indivíduos surdos.

Portanto, observa-se a necessidade que os indivíduos surdos têm de estabelecerem interações com seus pares surdos. Quando se faz referência à cultura surda, muitas vezes, percebe-se resistência e tendência a incluir os surdos no discurso da cultura universal. A cultura monolítica aproveita os discursos de eliminação das desigualdades para provocar uma identificação das minorias com a ideologia majoritária. Segundo Sá (2006) pela desautorização ou negação da diferença leva-se a uma 'amarração' da cultura surda a partir de um discurso de que uma sociedade igualitária é a sociedade perfeita. No entanto, há que se refletir se o ideal é que pessoas em condições diferentes sejam expostas e condicionadas à situações iguais. Terão todas as mesmas oportunidades?

O que deseja a comunidade surda não é o reconhecimento de uma cultura que os isola do mundo, até mesmo porque, segundo Skliar (2005, p.28) "Não me parece possível compreender ou aceitar o conceito de cultura surda senão através de uma leitura multicultural, ou seja, a partir de um olhar de cada cultura em sua própria lógica, em sua própria historicidade em seus próprios processos e produções". Consequentemente, não se pensa a cultura surda como oposto da cultura dos ouvintes ou como uma cultura patológica com base no déficit. Antes, como uma cultura visual com características próprias, mas interpenetrada e permeada pelas relações com outras manifestações culturais. 
Ainda segundo Skliar (2006), os surdos formam uma comunidade linguística minoritária que se caracteriza pela utilização de uma língua gestual visual e valores culturais, hábitos e modos de socialização próprios. Para o referido autor, a língua de sinais constitui o elemento identitário dos surdos e o fato de organizarem-se em comunidades indica que compartilham e conhecem as normas e formas de uso de uma determinada língua de sinais, por meio da qual interagem de forma natural e cotidiana, estabelecendo um processo comunicativo eficiente.

Sobre isso, Skliar (2006, p.102) acrescenta:

A comunidade surda se origina em uma atitude diferente frente ao déficit, já que não leva em consideração o grau de perda auditiva de seus membros. A participação na comunidade surda se define pelo uso comum da língua de sinais, pelos sentimentos de identidade grupal, o auto-reconhecimento e identificação como surdo, o reconhecer-se como diferentes, os casamentos endogâmicos, fatores estes que levam a redefinir a surdez como uma diferença e não como uma deficiência. Pode-se dizer, portanto, que existe um projeto surdo da surdez. A língua de sinais anula a deficiência e permite que os surdos consigam, então, uma comunidade linguística minoritária diferente e não um desvio da normalidade.

A partir de tal perspectiva, as manifestações de cultura surda passam a ser consideradas não como pertencentes a uma cultura patológica, mas como parte de uma cultura legítima, que de acordo com Sá (2006) "Só enriquece a visão do que é 'ser humano' - o ser que transcende a fala, mas não transcende a linguagem". Assim, o indivíduo surdo passa a ser entendido como diferente, não unicamente porque não ouve, mas porque desenvolve potencialidades psicoculturais diferentes, mas não opostas às dos ouvintes.

Sobre a constituição do sujeito cultural surdo, Perlin (2005, p.77-78), com a propriedade de quem fala por ser surda, argumenta:

A cultura também assume centralidade na constituição da subjetividade e da identidade
da pessoa como ator social. Essas marcas internas da diferença moldam as identidades
surdas. As identidades surdas são construídas dentro das representações possíveis da
cultura surda, elas moldam-se de acordo com a maior ou menor receptividade cultural as-
sumida pelo sujeito. E, dentro dessa perspectiva cultural, também surge àquela luta políti-
ca ou consciência oposicional pela qual o indivíduo representa a si mesmo, se defende
da homogeneização, dos aspectos que o tornam corpo menos habitável, da sensação de
invalidez, de inclusão entre os deficientes, de menos valia social. A cultura surda é o lugar
para o sujeito surdo constituir sua subjetividade de forma a assegurar sua sobrevivência e
a ter seu status quo diante das múltiplas culturas, múltiplas identidades.

Estamos vivendo em um mundo multifacetado e multicultural. Para Skliar (2005), a sociedade não é um todo unitário e os longos anos de autoritarismo e de negação da surdez caracterizaram-se como tentativa de anular culturas de resistência, que dentro de uma universalidade abstrata revelaram-se ameaçadoras e perigosas considerando seu potencial de desestabilização dos padrões impostos e a possibilidade de desintegração da ordem pré-estabelecida. Assim, consideramos neste estudo a existência da cultura surda como manifestação de um grupo que vive em comunidade e compartilha com seus pares uma língua viso-gestual, uma apropriação visual do mundo, assim como uma forma de viver e de organizar o tempo e o espaço exclusivamente por meio da experiência do ser surdo. Considerando, no entanto, que o indivíduo surdo é um ser multicultural constituído pelas diversas culturas que se interpenetram na constituição de sua subjetividade, e que a cultura surda não se constitui em oposição à cultura ouvinte, mas na constituição da subjetividade do indivíduo surdo. 


\section{5 | CULTURA SURDA: PARA QUEM?}

Continuando, podemos considerar que a significação de cultura se coloca mais complexa do que, simplesmente, ligada a uma questão linguística. Poder-se-ia dizer também, que uma língua, isoladamente, não constitui uma cultura. Os surdos não crescem isolados de uma sociedade com valores, crenças e símbolos, modos de agir e pensar de um sistema social instituído. Então, surdos e ouvintes são constituintes de um mesmo universo social. No entanto, faz-se necessário refletir sobre os sentidos que o social adquire para cada indivíduo e de que maneira a cultura significa e é significada por cada um.

De acordo com Gomes (2011, p.34): "Entender a cultura surda não se vincula à ideia de classificação ou a busca por uma exatidão conceitual. (...) a cultura surda não existe como realidade palpável a priori; ela acontece no interior das práticas discursivas." Portanto, leva-nos a refletir sobre os fenômenos discursivos em que se inserem os conceitos de cultura surda.

Para tanto, não se faz objetivo deste artigo afirmar sobre a existência ou não de uma cultura surda, mas refletir sobre as razões que levaram a cultura surda a se tornar uma necessidade de afirmação para a comunidade surda e os reflexos dessa necessidade na escola pública. Uma vez que para Lopes (2011, p.123):

A cultura surda vem atuando com um conceito fechado e universal, tomando significado de língua, essência, experiência visual, tradução cultural, entre tantos outros. Entretanto, esta busca por definição, por conceituação, paralisa-nos, deixa de nos fazer pensar no irreal, no devir.

Faz-se importante lembrar que o discurso cultural da surdez, agrega inúmeros enunciados que foram significados a partir das vivências do povo surdo, da história destes indivíduos e das experiências socialmente vividas por eles. Portanto, considerar o caráter de centralidade da linguagem permite-nos entender que tudo tem um caráter discursivo, o que significa que a realidade pode ser construída a partir da linguagem e das subjetividades dos indivíduos. Assim, de acordo com Lopes (2011, p.35):

Para além do processo de significação, a linguagem constitui uma realidade, e não apenas a relata, ou seja, ela inventa, cria uma verdade sobre algo. Saliento que as "coisas", ou melhor, "a materialidade das coisas", em seu sentido físico existe, mas a relação entre a sua existência e os significados que lhes damos é o que toma papel central nesta discussão.

Segundo o pensamento da autora, podemos afirmar que a cultura surda é uma realidade inventada discursivamente e não se trata de categorizar os artefatos de uma cultura surda, nem mesmo de afirmar sobre a sua veracidade ou dúvida. Interessa-nos, entender para quem ela significa e qual a importância desta realidade discursiva na educação de alunos surdos em escolas públicas.

Então, é interessante observarmos os discursos surdos sobre sua cultura e refletir sobre as significações que implicam nesta realidade. Assim, consideramos a afirmativa da professora surda Perlin (2006) ao afirmar:

A experiência da diferença cultural sentida e vivida por aqueles que têm a coragem de serem surdos é mais que dinâmica. O que obriga o surdo a travar lutas pela diferença? O ato de definição de nossa cultura é um espaço contraditório ao ouvinte. A luta pelas diferenças não pode ser explicada por simples oposições binárias, ela é uma estratégia de sobrevivência. A cultura surda existe enquanto estratégia de contra dominação. (grifo meu) As estratégias contêm posições de diferença, de identidade, de cultura, de política que se diferenciam em diferentes tempos. Diferenças que unem enquanto posições de luta pela identificação cultural. 
Percebemos que a autora situa o discurso da cultura surda num campo de lutas pela afirmação do indivíduo surdo e, mais ainda, afirma que o indivíduo surdo precisa ter coragem para narrar-se como surdo, como diferente, em oposição ao padrão de normalidade ouvinte. A autora considera que a afirmação da cultura surda não pode ser reduzida à simples oposições binárias. Não se trata de ser surdo em oposição ao ouvinte, mas de ser surdo constituinte de lutas culturais de solidificação.

Gomes (2011), afirma que durante anos os surdos foram constituídos pela narrativa da deficiência e ocupavam um lugar subalterno na estrutura social. A construção de identidade com base na falta, não lhes permitia a participação autônoma em sociedade. Assim, o discurso cultural vem socorrer, proteger e subverter esta lógica deficiente da surdez. Os indivíduos surdos se apoiaram no discurso da cultura surda como maneira de se auto afirmarem como constituintes de suas próprias narrativas.

Os indivíduos surdos foram negligenciados quanto ao direito de liberdade de pensamento e gerenciamento de suas próprias vidas em uma sociedade em que a violência dos dominadores se volta para aqueles que são considerados socialmente fracos. No pensamento de Adorno (2006, p.122):

\footnotetext{
Um esquema sempre confirmado na história das perseguições é o de que a violência contra os fracos se dirige, principalmente, contra os que são considerados socialmente fracos e ao mesmo tempo - seja isto verdade ou não - felizes. De uma perspectiva sociológica, eu ousaria acrescentar que nossa sociedade, ao mesmo tempo em que se integra, cada vez mais, gera tendências de desagregação. Essas tendências encontram-se bastante desenvolvidas logo abaixo da superfície da vida civilizada e ordenada. A pressão do geral dominante sobre tudo que é particular, os homens individualmente e as instituições singulares, tem uma tendência a destroçar o particular e individual justamente com seu potencial de resistência.
}

Junto com sua identidade e seu potencial de resistência, os indivíduos também perdem a capacidade de se contrapor ao instituído pela sociedade majoritária. E é justamente, contra essa suposta capacidade de destroçar o potencial de resistência das minorias, que a cultura surda se fortifica como discurso e como verdade para os indivíduos surdos.

\section{5 | CONSIDERAÇÕES FINAIS}

Na atualidade, as políticas públicas de educação propõem mudanças no ambiente, nas práticas pedagógicas e sociais produzidas no interior das instituições escolares na intenção de promover a participação e aprendizagem de todos os alunos. No entanto, ao pensarmos sobre o aprendizado e participação de alunos surdos, faz-se necessário considerar que as possibilidades de participação estão relacionadas às questões linguísticas e culturais no que tange ao acesso às informações, às relações estabelecidas com o meio e aos processos de formação de subjetividades destes indivíduos.

Nessa perspectiva, considerando a educação escolar de alunos surdos, faz-se necessário adentrar em questões linguísticas e culturais pertinentes aos processos de formação destes indivíduos. Assim como, considerar questões relativas às práticas que subjetivam indivíduos surdos e suas possibilidades de participação no contexto social em que estão inseridos.

De acordo com a legislação vigente, tomando por base a Lei Federal n 10.436/2002 (BRASIL, 2002), sabe-se que a Libras é considerada língua oficial da comunidade surda brasileira e que o Decreto 5626/2005 (BRASIL, 2005) regulamenta e institui diretrizes para a educação de surdos na perspectiva de educação bilíngue, considerando a Libras como primeira língua da comunidade surda brasileira e português como segunda língua, sendo assegurando a estes indivíduos os direitos 
de acesso à sua língua, profissionais capacitados nas escolas, adequações de currículo e avaliação, entre outros.

Nesse sentido, percebemos que a legislação vigente, se constitui na percepção de que a língua de sinais deve ser o agente possibilitador de acesso aos conhecimentos e aprendizagem escolar. No entanto, de acordo com Camatti e Gomes (2011, p.168): "por mais que a língua de sinais esteja presente em todos os espaços inclusivos de educação, a tradução sempre é feita a partir de um conjunto de ações pensadas anteriormente para o alunado ouvinte". E a presença da língua de sinais se constitui, apenas, como elemento tradutor de uma cultura e de uma lógica pensada de e para indivíduos ouvintes.

Nesse processo conflituoso e fronteiriço entre as línguas e as culturas interligadas é que acontece grande parte dos processos de subjetivação dos indivíduos surdos, do conhecimento sobre si mesmos e sobre os outros de produção de significados e das relações que se estabelecem com o entorno social. SegundoCamatti e Gomes (2011, p.168):

Muitas vezes, por meio de vivências e experiências, vai se instaurando no aluno surdo um sentimento de estrangeirismo da cultura da maioria ouvinte, da qual ele se sente hóspede, e a noção de pertencimento ao grupo escolar, torna-se mais distante.

As discussões sobre a questão cultural e sua relação com as práticas pedagógicas vêm sendo cada vez mais presentes e significativas no processo de escolarização. Faz-se importante pensar sobre o espaço e o papel que a cultura surda assume nas escolas públicas. Quando pensamos no atual processo de inclusão centrado em adaptações de estratégias e planos de aulas pensados para alunos ouvintes, podemos entender a necessidade que os alunos surdos demandam em afirmar a cultura surda nas escolas públicas e reconhecemos a cultura surda como um produto de afirmação desses indivíduos na intenção de narrarem-se a si mesmos diante da sociedade majoritária ouvinte.

Neste contexto, não cabe mais refletir sobre a acessibilidade da língua de sinais, uma vez que esta necessidade está posta. Mas, considerar os processos culturais como necessitando serem estruturados e viabilizados a partir da lógica do pensamento de indivíduos surdos, considerando suas subjetividades e produções discursivas em todo o processo pedagógico. Assim, as medidas adaptativas como a modificação de provas, a presença de intérpretes, adaptação curricular, entre outras, não atendem integralmente a demanda de alunos surdos nas escolas públicas. A demanda da cultura surda se insere em um contexto que respeite os discursos dos indivíduos surdos sobre o seu próprio processo educacional e isto implica em pensar a educação de surdos a partir de uma cultura surda, para que por meio dela possam se aproximar de outras línguas e outras culturas.

E ao considerarmos a educação de alunos surdos faz-se necessário atentar, para a segregação imposta pelo enfrentamento que se estabelece na afirmação da cultura surda como meio de legitimação das narrativas surdas e da identificação desses indivíduos com o seu processo de formação na escola pública e nas diversas dimensões sociais. Para que os indivíduos surdos possam se formar não como meros expectadores, mas que se constituam na e pela experiência educacional significativa. 


\section{Referências}

ADORNO, T. W. Educação e emancipação. São Paulo, Paz e Terra, 2006.

Indústria cultural e sociedade. Coleção Leitura. São Paulo: Paz e Terra, 2002.

BUENO, J. G. S. Surdez, linguagem e cultura. Caderno CEDES, vol.18, $\mathrm{n}^{\circ}$ 46, Campinas Sept. 1998. Disponível em http://dx.doi.org/10.1590/S0101-326219980003000 04. Acesso em: 18 agosto 2011.

BRASIL. Lei n. 10436, 24 abr.2002. Dispõe sobre a Língua Brasileira de Sinais - LIBRAS - e dá providências. Diário Oficial da União. Brasília, 2002.

Brasília, 2005 .

Decreto n. 5.626. Diário Oficial da União.

CAMATTI, L; GOMES, A.P.G. In: THOMA, A.S.\& HILLESHEIM.B.(orgs.). Políticas de inclusão: gerenciando riscos e governando as diferenças. Santa Cruz do Sul, EDUNISC, 2011.

CEVASCO, M.L. Dez lições sobre estudos culturais. Bomtempo, 2003.

CHAUÍ, M. H. Cultura e democracia.In: Crítica y emancipación. Revista latino americana de Ciencias Sociales. Año 1, no. 1 (jun. 2008). Buenos Aires: CLACSO, 2008 Disponível em: http://bibliotecavirtual.clacso.org.ar/ar/ libros/secret/CyE/cye3S2a.pdf. Acesso em: 17 agosto 2012.

CROCHÍK, J. L. Preconceito, indivíduo e cultura. São Paulo, Casa do Psicólogo, 2006.

DORZIAT, A. O outro da educação: pensando a surdez com base nos temas identidade/diferença, currículo e inclusão. Petrópolis, Vozes, 2009.

GOLDFELD, M. A criança surda: linguagem e cognição numa perspectiva sociointeracionista. São Paulo, Plexus, 2002.

GOMES, A. P. G. In: KARNOPP, L.B; KLEIN,M; LAZZARIN, M.L.L. (Orgs.). Cultura surda na contemporaneidade: negociações, intercorrências e provocações. Canoas, ULBRA, 2011.

HALL, S. A identidade cultural na pós-modernidade. Rio de Janeiro, DP\&A, 2006.

HORKHEIMER, M. \& ADORNO, T. W. A Indústria Cultural: o lluminismo como mistificação das massas. In: ADORNO, T. W. Indústria cultural e sociedade. Coleção Leitura. São Paulo, Paz e Terra, 2002, p. 7-80.

LARAIA, R. de B. Cultura: um conceito antropológico. Rio de Janeiro, Zahar, 2009.
LASTA.L.L.; HILLESHEIM.B. In: THOMA A.S.; HILLESHEIM.B.(Orgs.). Políticas de inclusão: gerenciando riscos e governando as diferenças. Santa Cruz do Sul, EDUNISC, 2011.

LOPES, M.C. Surdez e educação. Belo Horizonte, Autêntica, 2011.

MEIRELES, R. M. do P. L. Educação bilíngue de alunos surdos: experiências inclusivas na Escola Municipal Paulo Freire, Niterói (RJ). Dissertação de Mestrado em Educação, Universidade Federal Fluminense, Niterói, 2010.

PERLIN, G.T. In: THOMA \& LOPES, M. C.A. (Orgs.) Invenção da surdez: cultura, alteridade, identidade e diferença no campo da educação. Santa Cruz do Sul, EDUNISC, 2005.

PERLIN, G.T. In: THOMA \& LOPES, M. C.A. (Orgs.). Invenção da surdez II: Espaços e Tempos de Aprendizagem na Educação de Surdos. Santa Cruz do Sul, EDUNISC, 2006.

PERLIN, G.T. In: SKLIAR, C. A surdez: um olhar sobre as diferenças. (Org.) Porto Alegre, Mediação, 2005.

PORCHE,C. In: SANTANA, A. P. \& BERGAMO, A. Cultura e identidade surdas: encruzilhada de lutas sociais e teóricas. Educação \& Sociedade. Campinas, vol.26, n.91, p.565-582, Maio/Agosto, 2005. Disponível em: http://www.cedes.unicamp.br. Acesso: 17 agosto 2013.

QUADROS, R. M. de. Educação de surdos: a aquisição da linguagem. Porto Alegre, Artmed, 2008.

SÁ, N. R. L. de. Cultura, poder e educação de surdos. São Paulo, Paulinas, 2006.

Existe uma cultura surda? Disponível em: www.eusurdo.ufba.br/arquivos/cultura_surda.doc. Acesso: 25 julho 2013.

SANTANA, A. P.; BERGAMO, A.Cultura e identidade surdas:encruzilhada de lutas sociais e teóricas. Educação \& Sociedade. Campinas, vol.26, n.91, p.565-582, Maio/Agosto, 2005. Disponível em http://www.cedes. unicamp.br, acesso dia 17 de agosto de 2013.

SKLIAR, C. A surdez: um olhar sobre as diferenças. (org.) Porto Alegre, Mediação, 2005.

Atualidade da educação bilíngue para surdos. (Org.). Porto Alegre, Mediação, volume 1, 1998.

WOODWARD, K. In: SILVA, T.T. da S; (Org.) Identidade e diferença: a perspectiva dos estudos culturais. Petrópolis, Vozes, 2011. 